This item was submitted to Loughborough's Research Repository by the author.

Items in Figshare are protected by copyright, with all rights reserved, unless otherwise indicated.

\title{
Processing of ceramic-metal interpenetrating composites
}

PLEASE CITE THE PUBLISHED VERSION

PUBLISHER

(C) Elsevier

VERSION

AM (Accepted Manuscript)

LICENCE

CC BY-NC-ND 4.0

REPOSITORY RECORD

Binner, J.G.P., Hong Chang, and Rebecca L. Higginson. 2008. "Processing of Ceramic-metal Interpenetrating Composites". figshare. https://hdl.handle.net/2134/4059. 
This item was submitted to Loughborough's Institutional Repository (https://dspace.lboro.ac.uk/) by the author and is made available under the following Creative Commons Licence conditions.

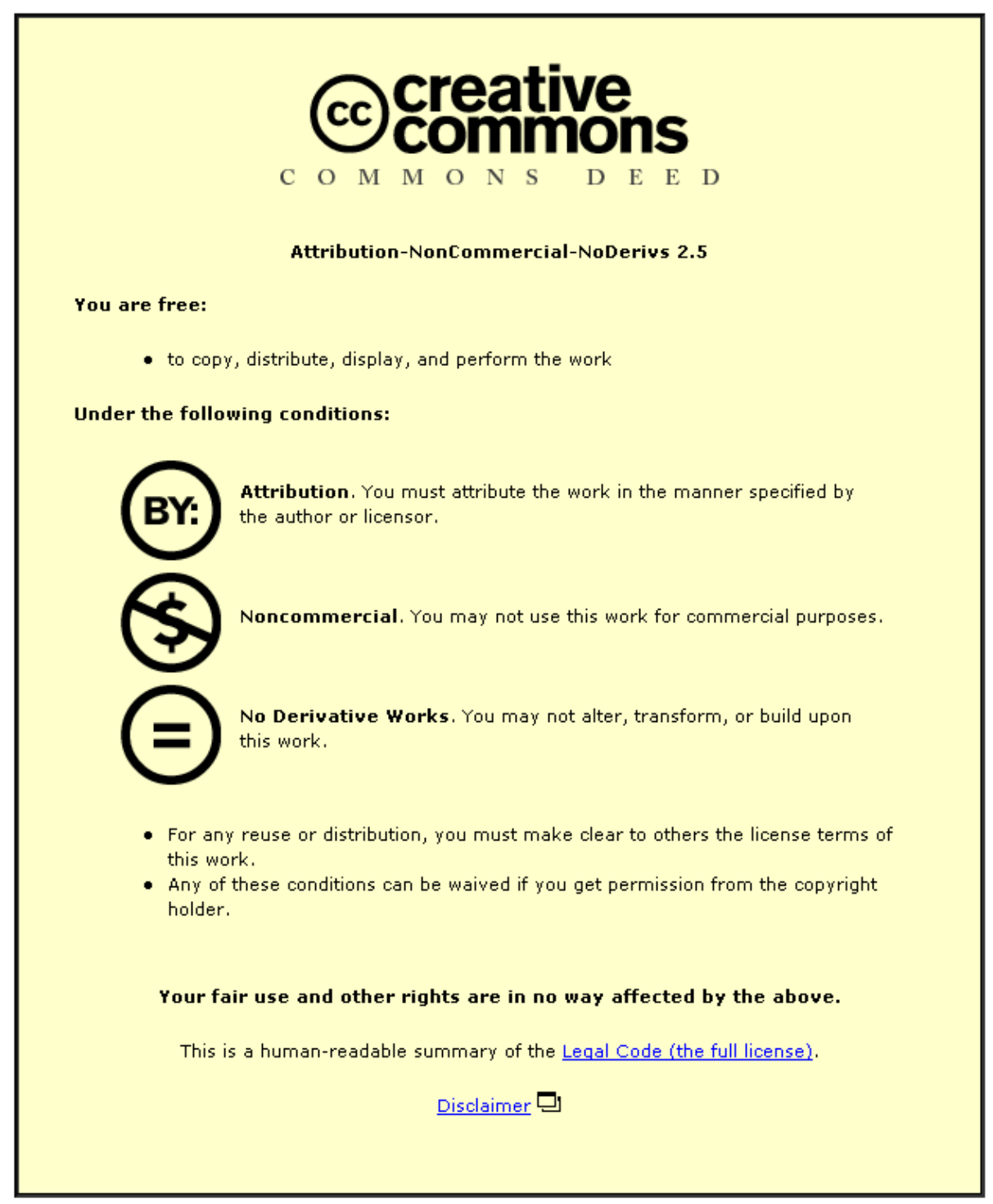

For the full text of this licence, please go to: http://creativecommons.org/licenses/by-nc-nd/2.5/ 


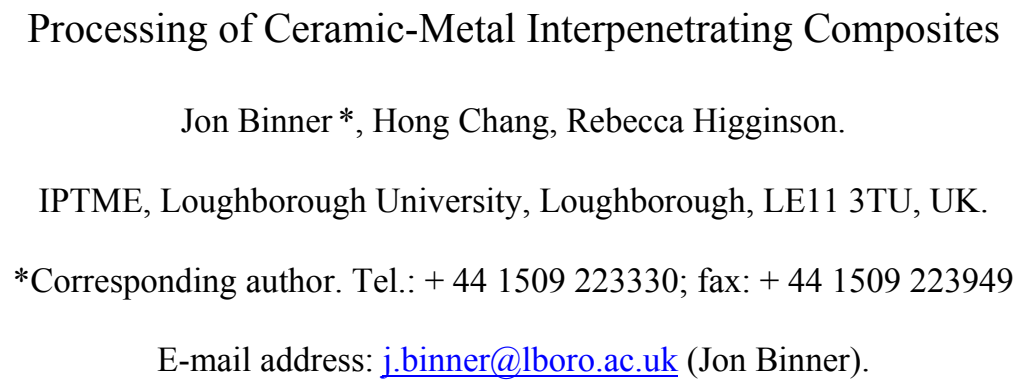

\begin{abstract}
Interpenetrating composites consist of 3-dimensionally interpenetrating matrices of two different phases; in the present work they were alumina and aluminium-magnesium alloys and were produced by infiltrating ceramic foams with molten alloys. The foams were made by mechanically agitating ceramic suspensions to entrain gases and then setting the structure via the in-situ polymerisation of organic monomers, a process known as gel casting. This resulted in the foams having a very open and interconnected structure that could be easily infiltrated by the molten metals. Previous composites have been produced at Loughborough University using squeeze casting; however, whilst infiltration was usually accomplished in a matter of seconds, the resulting size and shape of the composite was limited. Hence the present work has focused on investigating the potential for using gravity-fed infiltration. Whilst this was much slower, often taking several minutes, when optimised it is believed it will offer the potential for the production of large and complex-shaped pieces.
\end{abstract}

The composites were produced at atmospheric pressure by infiltrating 2-10 wt.\% magnesium content $\mathrm{Al}-\mathrm{Mg}$ alloys into $20 \%$ dense $\mathrm{Al}_{2} \mathrm{O}_{3}$ foams with highly interconnected porosity. The processing parameters of temperature, $\geq 900^{\circ} \mathrm{C}$, and atmosphere, flowing $\mathrm{N}_{2}$ Ar, were investigated to determine the processing window and infiltration kinetics. In-situ observation of the process shows that infiltration is faster at higher temperatures, $\mathrm{Mg}$ contents and $\mathrm{N}_{2}$ partial pressures. Both optical and scanning electron microscopy (SEM) have been used to characterize the composites. 
Key words Interpenetrating composites, pressureless infiltration, $\mathrm{Al}-\mathrm{Mg}$ alloys, $\mathrm{Al}_{2} \mathrm{O}_{3}$ foams, microstructure.

\section{Introduction}

There is a need to improve the mechanical and physical performance of metals such as aluminium and its alloys in order to extend their service limits in applications ranging from automotive components such as cylinder blocks, pistons and connecting rods, to aeroengine and airframe components, through spacecraft structures to heat sinks for electrical and electronic devices, sliding electrical contacts, golf clubs and bicycle frames ${ }^{1}$. A popular way of achieving this is through the addition of ceramic reinforcements. Commercial approaches to producing these composites involve either stirring particles into molten metals followed by casting or infiltrating densely-packed beds of either particles or fibres, both approaches yielding a discrete phase dispersed in an otherwise homogeneous matrix material. These processing routes have their limitations however, not least the inability to vary the volume fraction of ceramic above $\sim 20 \%$ for stir-casting and below $\sim 50 \%$ for metal infiltration. In addition, these routes also suffer from a lack of control of the structure, high processing costs and limitations in the range of product geometries that are possible.

Composites such as those outlined above are defined as $0-3$ and $1-3$ respectively $^{2}$, that is, whilst the matrix phase is continuous throughout the material, the dispersed phase is either not interconnected in any of the three dimensions (0-3) or, if continuous fibres are used, connected in a single dimension (1-3). However, a change in connectivity between the phases, from 1-1 (phases connected in a single dimension) through to 3-3 (both phases interpenetrating in all three dimensions) can result in substantially different properties. Although 3-3 connectivity is fairly common in natural composites, e.g. bones and wood, there have been relatively few attempts at creating it synthetically ${ }^{3}$. The difficulty with fabricating a truly interpenetrating network lies in achieving the required connectivity and 
spatial distribution of the phases, especially on a fine scale. However, the ability to fabricate by design such an interpenetrating microstructure raises the possibility of developing materials with truly multifunctional properties, each phase contributing its own characteristics to the macroscopic properties of the composite. For instance, one phase might provide high strength or wear resistance whilst the other contributes a different property such as electrical conductivity. The applications include light weight structural parts, wear resistant applications, and electrical and thermal components where good thermal conductivity, reduced coefficient of thermal expansion (CTE) and good electrical conductivity (via the connectivity of the metal) can be achieved. In addition, since many continuum properties change abruptly at the percolation threshold (the limit where connectivity is gained or lost), possibly the greatest potential for making materials capable of exhibiting novel behaviour lies with those that have marginally interconnected microstructures $^{3}$. This necessitates the ability to control the fraction and structure of both phases, preferably with a degree of independence. However until more of these interpenetrating composites are produced and their properties systematically investigated, there is little other guidance as to how the interconnectivity might affect the overall properties.

One route to achieving tailorable 3-3 composites is via the infiltration of a second phase into porous materials that display complete pore interconnectivity. Provided that the structure of the initial porous material can be controlled sufficiently in terms of the degree of porosity, the size and shape of the pores, the size of the windows between them and the nature of the struts separating them, then there is the opportunity to design and fabricate interpenetrating composites with customised structures. Hence the infiltration of cellular ceramics offers the potential for producing tailored 3-3 interconnectivity interpenetrating composites.

\section{Experimental}


Four aluminium-magnesium alloys containing approximately 2, 6, 8 and $10 \mathrm{wt} \% \mathrm{Mg}$ were produced from commercially pure aluminium and a Mg-Al master alloy, AZ81. The Al was melted in a covered clay-graphite crucible in air, then a piece of AZ81 of the correct size was immersed into the melt. After the AZ81 was melted, the melt was stirred using an $\mathrm{Al}_{2} \mathrm{O}_{3}$ rod, the slag was removed and the melt was poured into a steel mould. To compensate for $\mathrm{Mg}$ loss during casting, 16 wt.\% excess AZ81 ( 15 wt.\% Mg) was used for each composition. The initial microstructures consisted of course columnar grains for the 2 and $6 \mathrm{wt} \% \mathrm{Mg}$ alloys and dendritic columnar grains for the 8 and $10 \mathrm{wt} \% \mathrm{Mg}$ alloys. Al-Mg intermetallic phase, $\mathrm{Al}_{3} \mathrm{Mg}_{2}$, was observed in the 8 and $10 \mathrm{wt} \% \mathrm{Mg}$ alloys.

Following casting, sections were cut and ground on all surfaces using successively finer grades of $\mathrm{SiC}$ paper from 120 to 1200 grit to remove any defects or residual oxides. These samples were placed on top of blocks of alumina ceramic foam preform measuring $70 \times 20 \times$ 9 or $70 \times 20 \times 16 \mathrm{~mm}$ and manufactured by Dytech Corporation Ltd, UK, using a gel casting technique ${ }^{4}$. The foams had a density of $20 \%$, a spherical cell size of $\sim 350 \mu \mathrm{m}$, the latter being fully interconnected by windows with a diameter of $\sim 90 \mu \mathrm{m}$, fig. 1 .

To infiltrate the molten metals into the ceramic foams, the metal/ceramic assemblies were heated inside a tube furnace, fig. 2, at temperatures from 900 to $940^{\circ} \mathrm{C}$ using a heating rate of $30^{\circ} \mathrm{C} \mathrm{min}^{-1}$. Heating was performed in pure argon to minimise nitridation, once the desired temperature was reached the furnace atmosphere was either maintained as pure Ar or changed to Ar- $25 \% \mathrm{~N}_{2}, \operatorname{Ar}-55 \% \mathrm{~N}_{2}$ or $100 \% \mathrm{~N}_{2}$ (BOC Gases, oxygen free. $\mathrm{N}_{2}$, Manchester; Ar, Surrey). The process was monitored through a quartz window on the end of the furnace tube and the time for infiltration noted. The composites were then furnace cooled to room temperature in pure Ar.

After infiltration, samples of the composites were cut longitudely and mounted in Bakelite, prepared metallographically and examined optically in the as-polished condition. For this, the samples were anodized using fluroboric acid and observed using polarized light microscopy. 
The infiltration height was measured on the polished cross-section and the average infiltration rate of the sample was then calculated based on the infiltration height and time. Small unmounted samples were also surface ion beam milled to obtain a good enough finish for EBSD to be performed. The samples were examined in a LEO VP 1530 FEG SEM equipped with a TSL EBSD which has the capacity to collect simultaneous EDS data. The samples were inclined to $70^{\circ}$ using a pre-tilted holder and the SEM was operated at $20 \mathrm{kV}$. Processing of the data was carried out using OIM analysis with the results presented as Inverse Pole Figure (IPF) maps or chemical EDS maps. No cleaning algorithm was applied to any of the data collected.

\section{Results and Discussions}

Fig. 3 shows the infiltration rate as a function of the processing parameters investigated, viz. (a) magnesium content in the aluminium alloy, (b) furnace atmosphere and (c) temperature. It can be seen that the infiltration rate increased with increasing magnesium content, the fraction of nitrogen present in the atmosphere and the infiltration process temperature. Given that the only driving forces in the system were from capillary action and gravity (since the infiltration direction was downward), and the latter was the same for all experiments, the results in fig. 3a can be explained by the increased wettability of the alloys that contained more magnesium. With respect to the furnace atmosphere, fig. $3 b$, the maximum rate was achieved when the infiltration took place in $100 \%$ nitrogen, although it was observed that to minimise nitridation an argon atmosphere was required during heating and cooling of the samples. Saravanan et. $a l^{5}$ studied the effect of nitrogen on the surface tension of pure aluminium and concluded that for temperatures higher than $850^{\circ} \mathrm{C}$, nitrogen decreases the surface tension well below that obtained in pure argon as a result of the formation of aluminium nitride. EDS analysis was performed on the composite produced at $900^{\circ} \mathrm{C}$ in a $100 \%$ nitrogen atmosphere, where nitridation of the alloy was identified ${ }^{6}$. This 
was not unexpected, as at the processing temperature of $915^{\circ} \mathrm{C}$ and a $100 \% \mathrm{~N}_{2}$ atmosphere, $\mathrm{AlN}$ is thermaldynamically stable ${ }^{7}$, although the nitridation process may be complex. Hence, whilst it was believed desirable to minimise the extent of nitridation of the alloy, the formation of some nitride during infiltration probably facilitated the infiltration. As far as the influence of temperature on the infiltration process was concerned, fig. $3 \mathrm{c}$, it can be seen that to obtain substantial infiltration a minimum temperature of around $910^{\circ} \mathrm{C}$ was required. Studies on the wettability of molten aluminium on alumina ${ }^{8}$ have shown that the contact angle decreases with increasing temperature and hence less time is needed for wetting at higher temperatures. Hence, as expected, wettability underpins all three results.

Fig. 4 shows the effect of the furnace atmosphere on the composite microstructure. With just $25 \%$ nitrogen, fig. $4 \mathrm{a}$, the pores in the ceramic foams were incompletely filled with the alloy, whilst at 55\% nitrogen and above, fig. $4 \mathrm{~b}$ and c, the pores were completely filled and there was little residual porosity. Note that in fig. $4 \mathrm{~b}$ a second phase may be observed at the interface between the infiltrated metal and the ceramic foam walls, this will be discussed further below. For the pure nitrogen atmosphere, fig. 4c, this second phase appeared to be homogeneously spread throughout the metal.

Fig. 5 shows a back-scattered electron micrograph and EDS maps for a sample infiltrated under the same conditions as that shown in fig. 4c. The structure within the Al-Mg alloy can be clearly seen and consists of a number of acicular particles and a two-tone grey structure; the darker grey being present either throughout the alloy within each pore or being more concentrated near the metal/ceramic interface. Whilst, as expected, the aluminium and oxygen concentrations were highest within the metal and ceramic respectively, fig.s $5 \mathrm{~b}$ and c, the darker grey structure in fig. 5a appears to correlate with a reduction in the aluminium concentration within the pores, fig. 5b. Interestingly, the magnesium concentration, fig. $5 \mathrm{~d}$, shows the opposite distribution, being greatest where the aluminium concentration was lowest within the alloy. Magnesium is critical to the infiltration process, although the 
mechanism is probably complex. Whilst it is known to be a good surfactant, increasing the wettability of the aluminium alloy ${ }^{9}$, it is also a strong oxygen scavenger and may therefore reduce any surface oxide on the metal, again aiding infiltration. Note that there were other very local areas within the grains that had a very high magnesium concentration, fig. $5 \mathrm{~d}$, but which are not evident on the back-scattered image, fig. 5a. These are not associated with the grey structure and appear to be second phase particles contained within the aluminium alloy grains. The iron map, fig. 5e, shows clearly that the acicular particles were iron rich. Present as an impurity within the alloy, it may be a result of iron pick up from the steel block used as a support for the composites during infiltration. Further work is needed to investigate the extent of iron contamination within the composites. Whilst the nitrogen map (not shown here) was unable to detect any difference in nitrogen content across the structure, XRD analysis on the composites infiltrated in $55 \%$ and $100 \% \mathrm{~N}_{2}$, fig. 6 , shows that besides aluminium and alumina, AlN formed in both the composites.

Fig. 7a shows an image quality / inverse pole fig. EBSD map of the Al-10\%Mg alloy infiltrated under pure nitrogen. Whilst the pattern quality obtained from both the alumina and the aluminium were good and image quality is high over the scan area, the step size used in the scan was too coarse to yield full detail of the alumina structure. However, it is clear that the aluminium within each cell has the same orientation and that each of the individual cells has a different orientation, although they tend towards (001) and (101) type orientations parallel to the infiltration direction. Fig. $7 b$ shows a phase map with the aluminium and alumina clearly defined. The un-indexed areas are believed to be porosity. There are two types, the irregularly shaped region near the top left of the image either represents an uninfiltrated pore or, more likely, alloy pull out during specimen preparation, whilst the curved regions around the edges of the cells may be due to shrinkage of the metal on cooling, although the latter also seem to coincide with an increase in the magnesium concentration, fig. 7c. Fig. 8 shows a scan over a single cell, in the same sample as fig. 7, which contains 
two alloy grains with a grain boundary that runs across the cell. Fig. 8b shows an EDS map for magnesium that indicates that there were a number of magnesium-rich particles on the grain boundary. It is postulated that the magnesium seen in the grains in fig. 7 may have initially precipitated on grain boundaries but, due to the high processing temperatures, the grain boundaries have migrated away from the magnesium precipitates. Microstructure of the composite at the $\mathrm{Al}(\mathrm{Mg})-\mathrm{Al}_{2} \mathrm{O}_{3}$ interface has been characterised using Transmission Electron Microscopy (TEM) on the dual beam Focused Ion Beam (FIB) prepared samples, in which AlN and $\mathrm{MgAl}_{2} \mathrm{O}_{4}$ spinel were identified at the metal-ceramic interface and the possible interfacial reactions have been discussed ${ }^{10}$.

\section{Conclusions}

Interpenetrating composites of aluminium-magnesium alloys in alumina have been made using pressureless infiltration; samples measuring $9 \mathrm{~mm}$ in height could be be fabricated in just 10 minutes under the optimum conditions. The latter include temperatures $\geq 910^{\circ} \mathrm{C}$, a pure nitrogen atmosphere and at least $10 \mathrm{wt} \%$ magnesium in the aluminium alloy. Although microstructural analysis has shown that as the nitrogen concentration increases the porosity within the cells decreases, there is an increase in the presence of a second phase within the metal. This appears to be magnesium-rich although further work is needed to ascertain its true nature and effect during processing and on the final properties of the composite. EBSD has been used to show that under optimum infiltration conditions the alumina pores are generally filled with a single crystallographic orientation of Al-Mg alloy. Whilst premature termination of infiltration has often been reported by other researchers, this was not observed in the current work, which suggests that it is potentially possible to obtain composites several centimeters high.

\section{Acknowledgements}


The authors gratefully acknowledge funding from the EPSRC in the UK and the foam samples from Dytech Corp. Ltd.

\section{References}

1. Taya, M. \& Arsenault, R. J., Metal Matrix Composites, Pergamon Press, Oxford, UK, 1989.

2. Newnham, R. E., Skinner, D. P. \& Cross, L. E., Connectivity and PiezoelectricPyroelectric Composites. Mat. Res. Bull., 1978, 13, 525-536.

3. Clarke, D. R., Interpenetrating phase composites. J. Am. Ceram. Soc., 1992, 75, 739-759.

4. Sepulveda, P. \& Binner, J. G. P., Processing of cellular ceramics by foaming and in situ polymerisation of organic monomers. J. Eur. Ceram. Soc., 1999, 19, 2059-2066.

5. Saravanan, R. A., Molina, J. M., Narciso, J., García-Cordovilla, C. \& Louis, E., Effects of nitrogen on the surface tension of pure aluminium at high temperatures. Scripta Materialia, 2001, 44, 965-970.

6 Chang, H., Binner, J. G. P., Higginson, R. L. \& Sambrook, R., Processing of Al-Mg/ $\mathrm{Al}_{2} \mathrm{O}_{3}$ interpenetrating composites by pressureless infiltration. In Proceedings of the $67^{\text {th }}$ World Foundry Congress. 2006, 201/1-201/8, [CD ROM].

7. Hou Q. H., Mutharasan R. and Koczak M., Feasibility of aluminium nitride formation in aluminum alloys, Materials Science and Engineering A., 1995, 195, 121-129.

8. Ksiazek, M., Sobczak, N., Mikulowski, B., Radziwill, W. \& Surowiak, I., Wetting and bonding strength in $\mathrm{Al} / \mathrm{Al}_{2} \mathrm{O}_{3}$ system. Mat. Sci. Eng. A, 2002, A324 [1-2], 162-167.

9. Zhou, X. B. \& De Hosson, J. T. M., Reactive wetting of liquid metals on ceramic substrates. Acta Mater., 1996, 44 [2], 421-426.

10. Chang, H., Higginson, R. L. and Binner, J. G. P., Interface Study by Dual Beam FIBTEM in a pressureless infiltrated $\mathrm{Al}-\mathrm{Mg} / \mathrm{Al}_{2} \mathrm{O}_{3}$ Interpenetrating Composite, in preparation. 

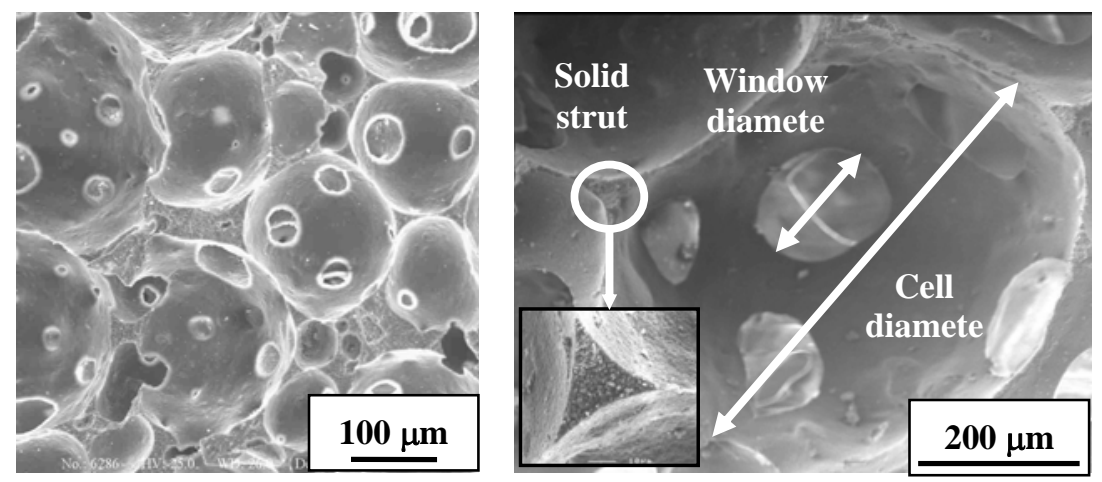

Fig. 1. Typical structure of the ceramic foams made by the gel casting process.

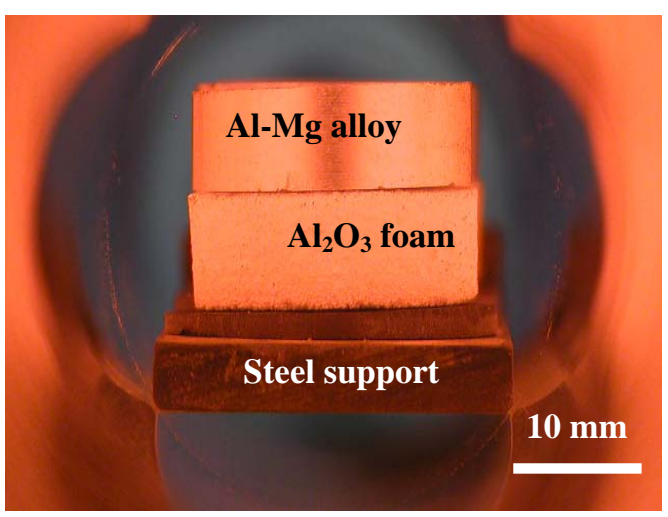

Fig. 2. The experimental arrangement for the pressureless infiltration of ceramic foams with alloy.
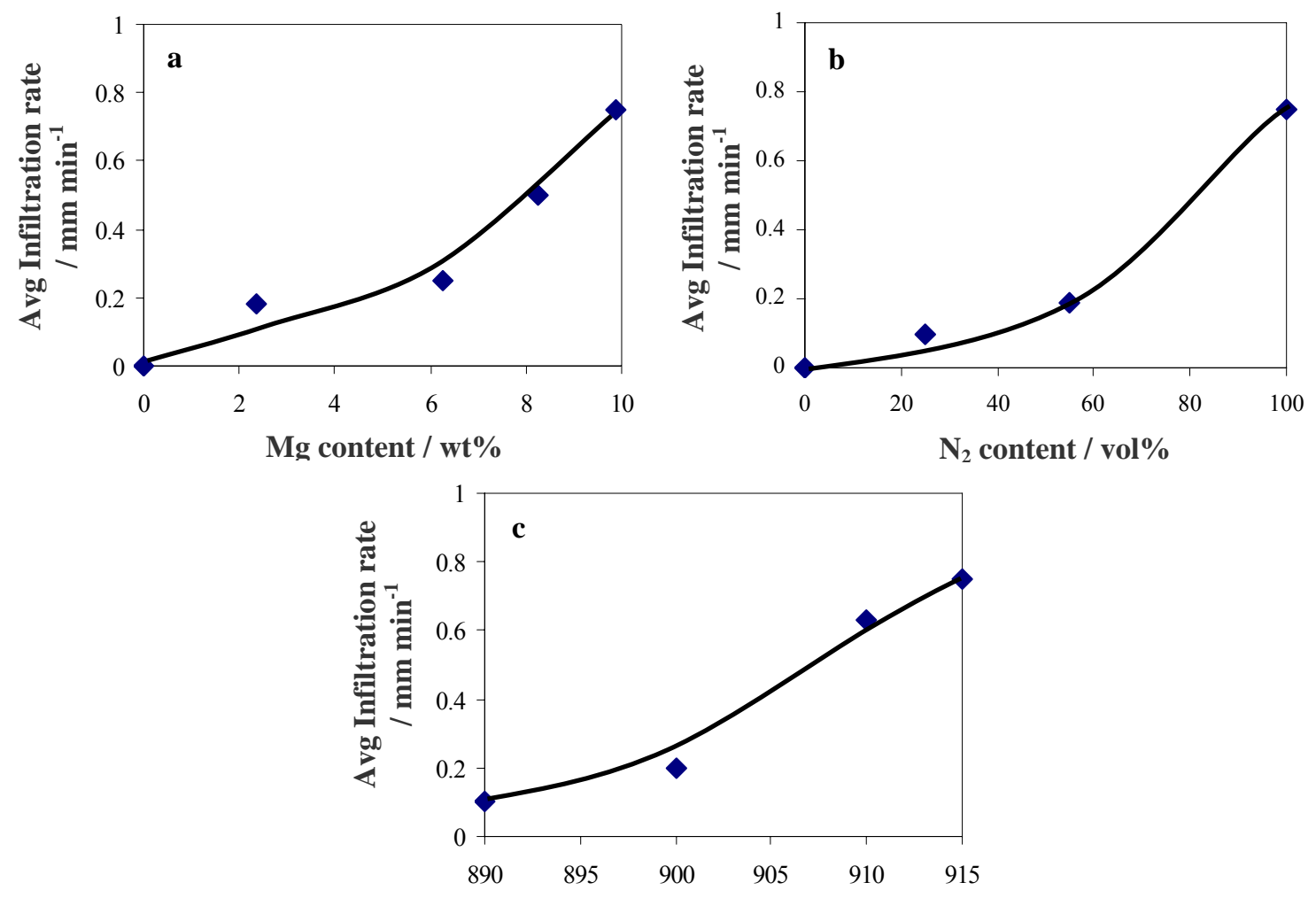

Temperature $/{ }^{\circ} \mathrm{C}$

Fig. 3. Infiltration rate of $\mathrm{Al}-\mathrm{Mg}$ alloys into $\mathrm{Al}_{2} \mathrm{O}_{3}$ foams with a cell size of $\sim 350 \mu \mathrm{m}$ versus (a) wt $\% \mathrm{Mg}$ at $910^{\circ} \mathrm{C}$ in pure nitrogen, (b) nitrogen content in the furnace atmosphere (balance argon) for $10 \mathrm{wt} \% \mathrm{Mg}$ at $910^{\circ} \mathrm{C}$ and (c) temperature for $10 \mathrm{wt} \% \mathrm{Mg}$ in pure nitrogen. 

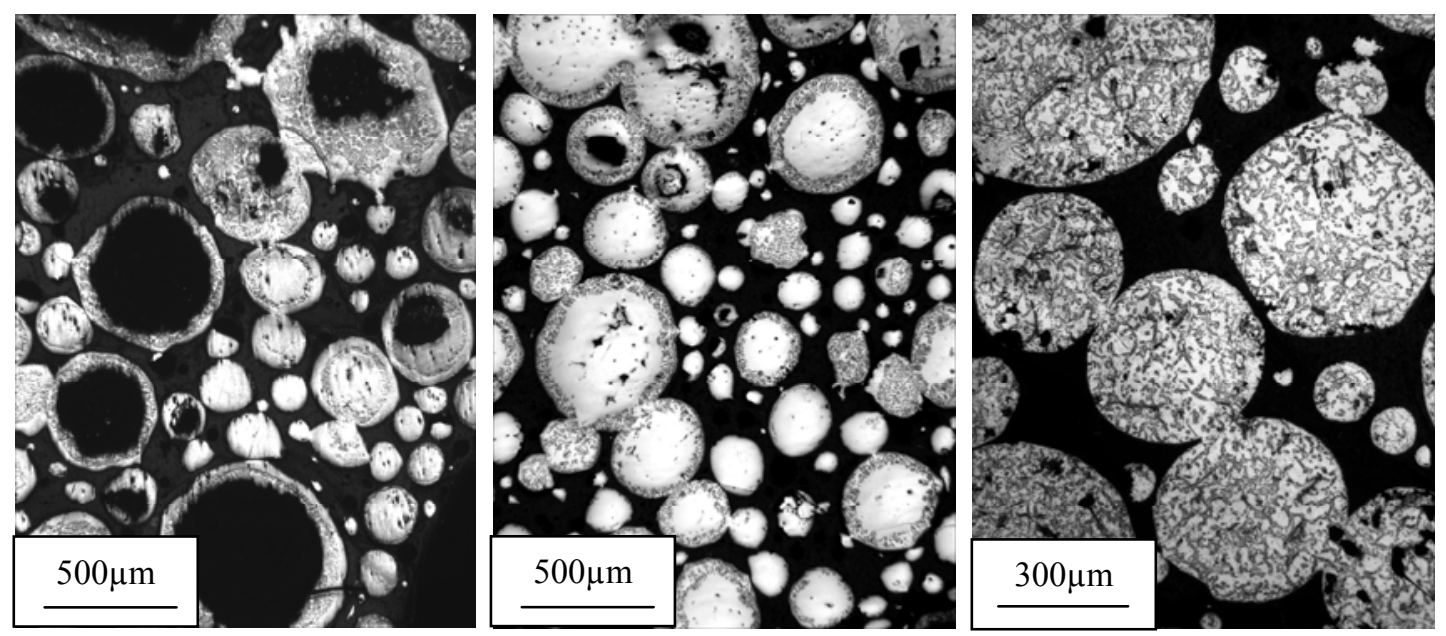

Fig. 4. Optical micrographs of the $\mathrm{Al}_{2} \mathrm{O}_{3}$ foam / $\mathrm{Al}-10 \% \mathrm{Mg}$ composite infiltrated in (a) $25 \%$ nitrogen, (b) $55 \%$ nitrogen and (c) 100\% nitrogen (balance argon).

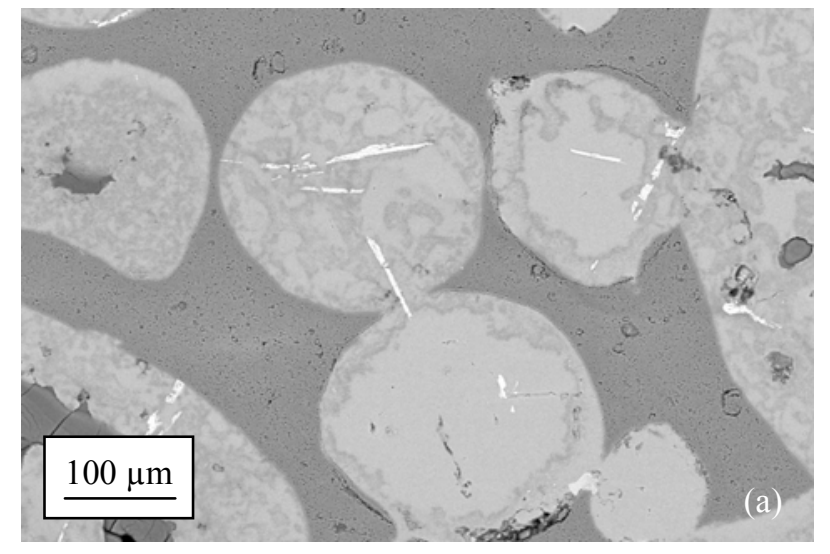

Low
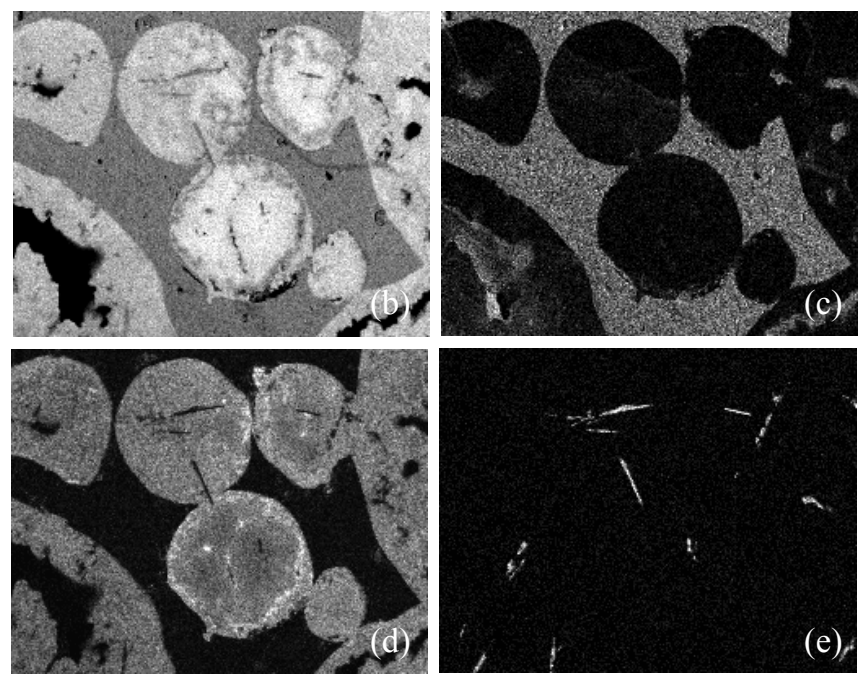

Fig. 5. (a) Back-scattered electron micrograph of an $\mathrm{Al}_{2} \mathrm{O}_{3} / \mathrm{Al}-10 \% \mathrm{Mg}$ composite processed in $100 \%$ nitrogen, with EDS maps for (b) aluminium, (c) oxygen, (d) magnesium and (e) iron. 


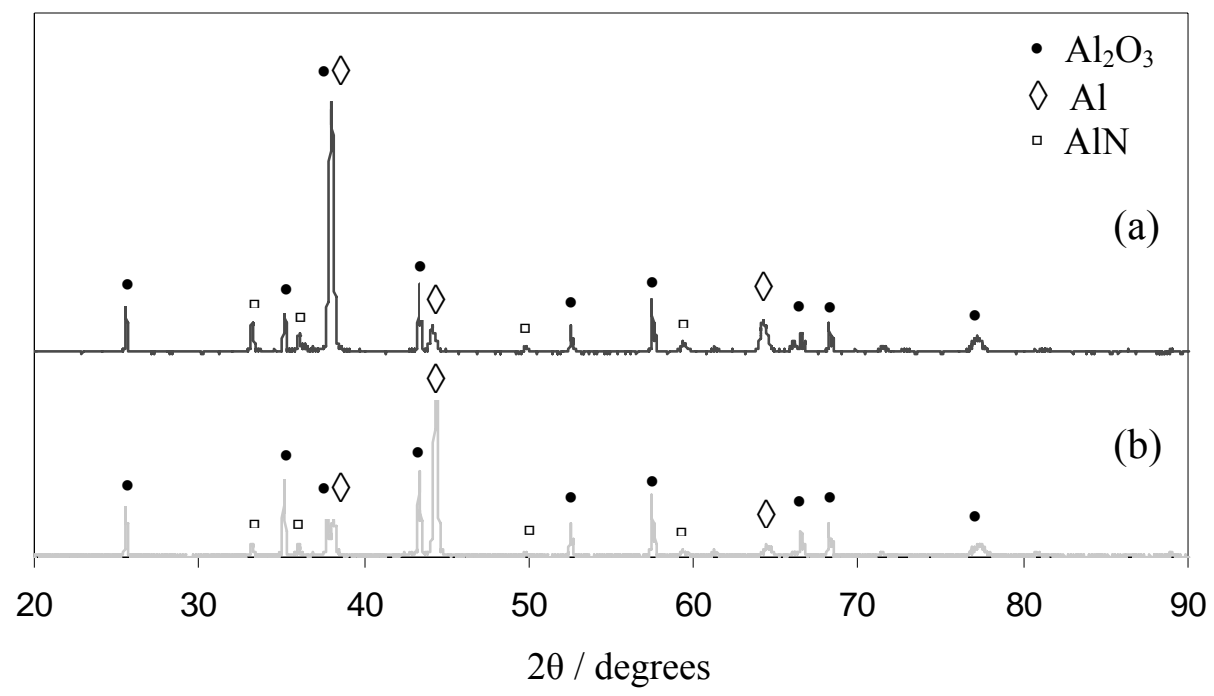

Fig. 6. X-ray analysis of the $\mathrm{Al}_{2} \mathrm{O}_{3} / \mathrm{Al}-10 \% \mathrm{Mg}$ composites processed both at $915^{\circ} \mathrm{C}$ (a) in $100 \%$ nitrogen; (b) $55 \%$ nitrogen. 

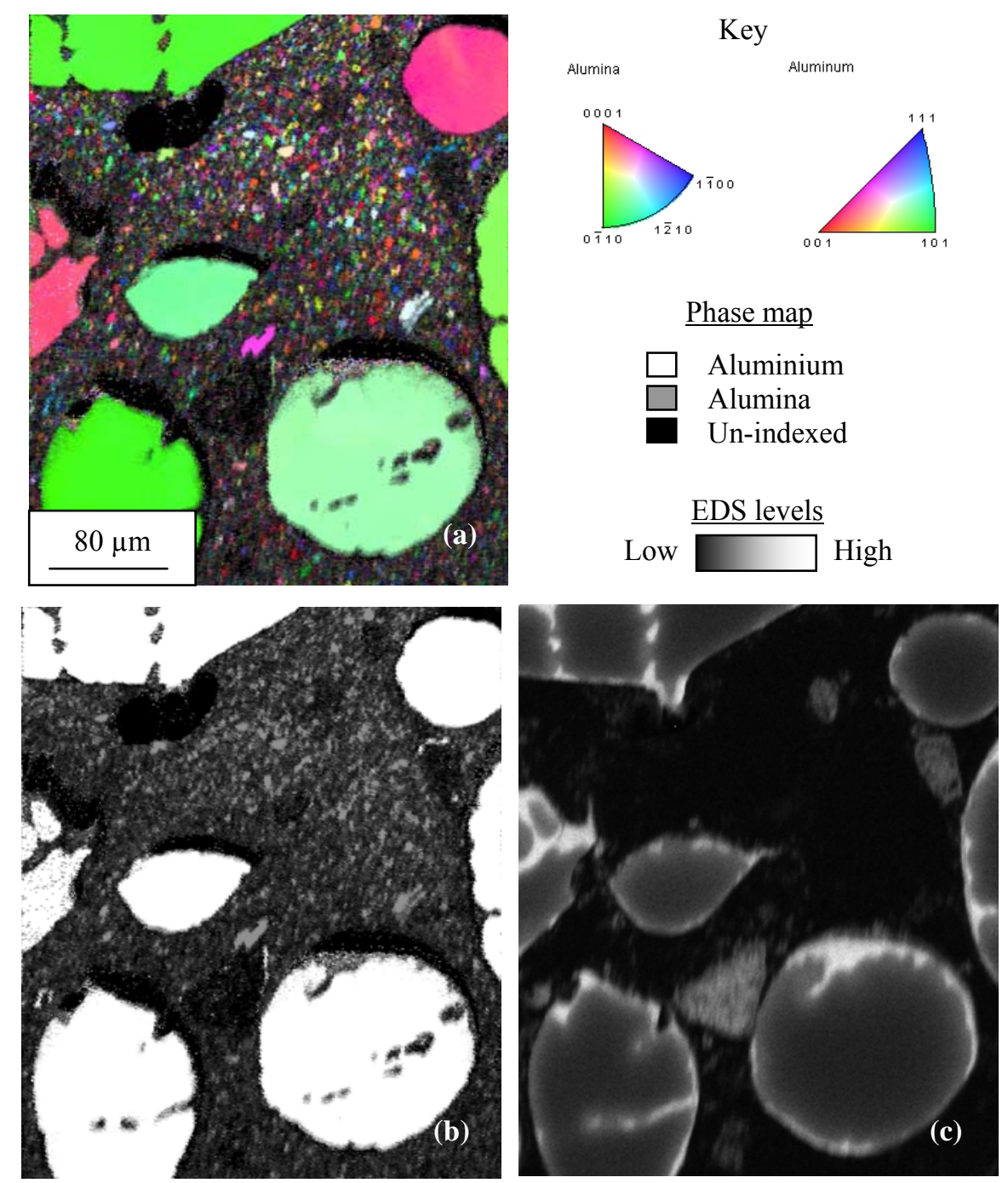

Fig. 7. (a) Image quality (IQ) / inverse pole figure plot for an $\mathrm{Al}_{2} \mathrm{O}_{3} / \mathrm{Al}-10 \% \mathrm{Mg}$ composite processed in $100 \%$ nitrogen, with (b) a phase map and (c) an EDS map for magnesium.
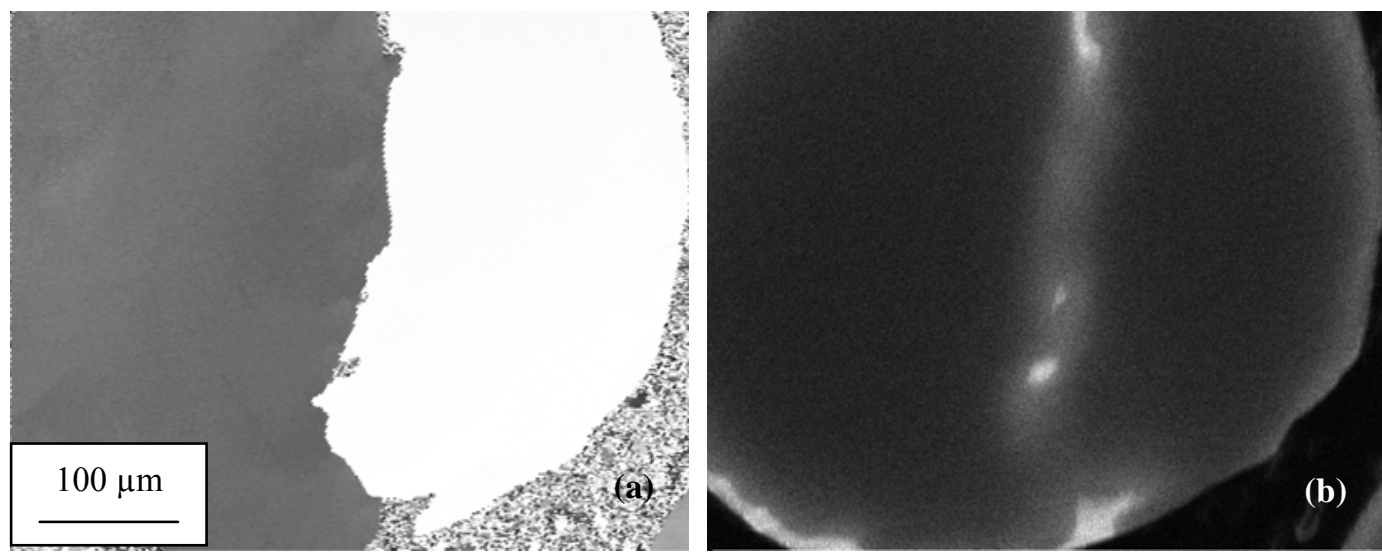

Fig. 8. Inverse pole figure plot of a composite of $\mathrm{Al}_{2} \mathrm{O}_{3}$ and $\mathrm{Al}-10 \% \mathrm{Mg}$ in $100 \%$ nitrogen showing (a) a cell containing two aluminium grains and (b) the corresponding EDS map for magnesium. 